\title{
Hypoxia induces pulmonary arterial fibroblast proliferation, migration, differentiation and vascular remodeling via the PI3K/Akt/p70S6K signaling pathway
}

\author{
XIAOYU CHAI ${ }^{1,2}$, DAN SUN ${ }^{1}$, QIAN HAN ${ }^{1,2}$, LIANG YI ${ }^{1,2}$, YANPING WU $^{1,2}$ and XINMIN LIU ${ }^{1}$ \\ ${ }^{1}$ Department of Geriatrics, Peking University First Hospital, Beijing 100034; \\ ${ }^{2}$ First Clinical Medical College of Peking University Health Science Center, Beijing 100083, P.R. China
}

Received March 18, 2017; Accepted November 29, 2017

DOI: $10.3892 /$ ijmm.2018.3462

\begin{abstract}
The present study was designed to examine whether hypoxia induces the proliferation, migration and differentiation of pulmonary arterial fibroblasts (PAFs) via the PI3K/Akt/p70S6K signaling pathway. PAFs were subjected to normoxia $\left(21 \% \mathrm{O}_{2}\right)$ or hypoxia $\left(1 \% \mathrm{O}_{2}\right)$. The proliferation, migration, differentiation and cellular $\mathrm{p} 110 \alpha$, p-Akt, and p-p70S6K expression levels of the PAFs were examined in vitro. In addition, rats were maintained under hypoxic conditions, and the right ventricular systolic pressure (RVSP), right ventricular hypertrophy index (RVHI) and right ventricular weight/body weight ratio (RV/BW) were examined. The expression levels of p110 $\alpha$, p-Akt, p70S6K, fibronectin and $\alpha$-SMA in the rat pulmonary vessels were also examined. Hypoxia significantly elevated the proliferation, migration and differentiation of rat PAFs. It also strongly elevated the expression of p110 $\alpha$, p-Akt and p-p70S6K in PAFs in vitro. NVP-BEZ235 was revealed to significantly reduce the hypoxia-induced proliferation, migration and differentiation. In vivo experiments demonstrated that hypoxia significantly induced the elevation of RVSP, RVHI, RV/BW, medial thickening, adventitious thickening, and fibronectin and collagen deposition around pulmonary artery walls. The expression of p110 $\alpha, \mathrm{p}-\mathrm{Akt}$ and $\mathrm{p} 70 \mathrm{~S} 6 \mathrm{~K}$ was evident in the pulmonary arteries of the hypoxic rats. NVP-BEZ235 significantly reduced the hypoxia-induced hypoxic pulmonary vascular remodeling, as well as fibronectin and collagen deposition in the pulmonary arteries. Therefore, hypoxia was demonstrated to induce the proliferation, migration and differentiation of PAFs and the hypoxic pulmonary vascular remodeling of rats via the PI3K/Akt/p70S6K signaling pathway.
\end{abstract}

Correspondence to: Dr Xinmin Liu, Department of Geriatrics, Peking University First Hospital, 8 Xishiku Street, Beijing 100034, P.R. China

E-mail:1xm2128@163.com

Key words: hypoxia, phosphatidylinositol-3-kinase, pulmonary arterial fibroblasts, proliferation, vascular remodeling

\section{Introduction}

Hypoxic pulmonary hypertension (HPH) is common in patients with pulmonary diseases $(1,2)$. The leading cause of HPH is alveolar hypoxia due to chronic lung disease (3). Hypoxia may produce mild to moderate pulmonary vascular remodeling, which may lead to a detrimental increase in pulmonary artery pressure and dysfunction of the pulmonary vascular regulatory mechanisms. Hypoxia-induced pulmonary changes may contribute to the development of sustained HPH $(4,5)$. Pulmonary vascular remodeling is a complicated pathological process that involves all layers of the vascular wall (6). Previous research has identified the roles of pulmonary arterial fibroblasts (PAFs) within the lungs, and established the primary cellular constituents of the vascular adventitia (7-10). PAFs have been reported to undergo the earliest and most significant proliferation in all layers of the vascular wall in HPH models (10). They also migrate to the intima and may be associated with neointima formation (10-12). The activation of PAFs by a variety of stimuli triggers their differentiation into myofibroblasts, which have been implicated as key participants in tissue remodeling $(7,13)$.

However, the mechanisms underlying the hypoxia-induced proliferation, migration and differentiation of PAFs remain unclear (14). Previous studies revealed that hypoxia inducible factor-1, mitogen activated protein kinase, transforming growth factor- $\beta$ (TGF- $\beta$ ), fibroblast grow factor- 2 (FGF2), osteopontin, macrophage migration inhibitory factor and 15-lipoxygenase (15-LO) are associated with the hypoxia-induced proliferation, migration, protein synthesis and phenotypic change behaviors of PAFs $(9,15-22)$. The platelet-derived growth factor $\beta$-receptor/c-Jun N-terminal kinase (JNK), TGF- $\beta 1 /$ FGF2 and JNK/15-LO/p2 $7^{\mathrm{kipl}}$ signaling pathways have been reported to participate in the regulation of hypoxia-induced PAF proliferation and differentiation (23). Further research is required to investigate the in-depth mechanisms underlying hypoxia-induced alterations in PAFs.

Previous studies demonstrated that the phosphatidylinositol-3-kinase (PI3K)/mammalian target of rapamycin (mTOR) signaling pathway serves an important role in cell proliferation, metabolism, protein synthesis and angiogenesis $(24,25)$. PI3K may be triggered by a variety of upstream signals and regulates 
the activity of various downstream effectors, including protein kinase B (Akt), mTOR and p70 ribosomal protein S6 kinase (p70S6K), through its phosphorylation activity (26). Negative feedback regulation of the Akt signaling pathway has been hypothesized to exist, but is not fully understood (26). Under hypoxic conditions, certain cells, including pulmonary arterial smooth muscle, A549 and porcine coronary artery endothelial cells and rat hepatocytes may exhibit activation of the PI3K/Akt signaling pathway, whereas others, including 293T, PC-3 and COS-7 cells, do not exhibit increased phosphorylation levels of Akt $(25,27)$. Previous studies have demonstrated that the $\mathrm{PI} 3 \mathrm{~K} / \mathrm{Akt} / \mathrm{p} 70 \mathrm{~S} 6 \mathrm{~K}$ signaling pathway is associated with the progression of HPH and the activities of cells in the pulmonary arteries $(25,27)$. The PI3K/Akt/p70S6K signaling pathway may be associated with the regulation of PAF proliferation, migration and differentiation under hypoxia (28). Previous studies revealed that PAFs from young cows had transiently upregulated PI3K expression when exposed to hypoxia, and demonstrated that the moderate hypoxia-induced $\left(3 \% \mathrm{O}_{2}\right)$ proliferation of fetal bovine PAFs required activation of the PI3K/Akt signaling pathway $(28,29)$. However, the underlying mechanism by which the PI3K/Akt/p70S6K signaling pathway contributes to the hypoxia-induced proliferation, migration, differentiation and pulmonary vascular remodeling in rat PAFs has not been identified. Therefore, the present study was undertaken to investigate whether the PI3K/Akt/p70S6K signaling pathway is associated with the proliferation, migration, differentiation and pulmonary vascular remodeling of PAFs under hypoxic conditions.

\section{Materials and methods}

Animal care and ethics. Experiments were performed using specific pathogen-free male Sprague-Dawley (SD) rats (Vital River; Charles River Laboratories International, Inc., Wilmington, MA, USA). The Peking University First Hospital Ethical Review Committee for Animal Experiments approved all animal protocols used in the present study (permit number, J201533). Applicable international and national institutional guidelines for the care and use of animals were followed. Procedures were consistent with the Guide for the Care and Use of Laboratory Animals (30). The procedures performed in the present study involving animals were in accordance with the ethical standards of the institution at which the studies were conducted. All efforts were made to ensure the comfort of the animals, and to minimize the number of animals used and their suffering.

Cell culture. Primary PAFs were isolated from the pulmonary arteries adventitia of male SD rats $(100 \pm 20 \mathrm{~g}$, aged 4-6 weeks, $\geq 2$ rats per primary PAF culture) using a dissecting microscope. Cells were cultured in high glucose Dulbecco's modified Eagle's medium (DMEM; HyClone; GE Healthcare Life Sciences, Logan, UT, USA), supplemented with 100 U/ml penicillin, $100 \mathrm{~g} / \mathrm{ml}$ streptomycin (both Beyotime Institute of Biotechnology, Haimen, China) and $10 \%$ fetal bovine serum (FBS; Gibco; Thermo Fisher Scientific, Inc., Waltham, MA, USA), in a humidified incubator with $5 \% \mathrm{CO}_{2}$ at $37^{\circ} \mathrm{C}$. Cells were purified and identified using the fibroblast marker vimentin (cat. no. 5741; Cell Signaling Technology, Inc.,
Danvers, MA, USA), which was detected via immunofluorescence after culturing for 3 passages; only passages 3-6 were used in the experiments. For all assays, unless otherwise specified, cells were plated at a density of $5 \times 10^{5}$ cells $/ \mathrm{cm}^{2}$, cultured to $80 \%$ confluence, starved and growth arrested in DMEM without serum for $24 \mathrm{~h}$ and subsequently used in the experiments. Pretreatment with inhibitors, NVP-BEZ235 as a dual PI3K/mTOR inhibitor, LY294002 as a PI3K inhibitor and rapamycin as an mTOR inhibitor (all from Selleck Chemicals, Houston, TX, USA), was achieved by adding the inhibitor $1 \mathrm{~h}$ prior to stimulation in the absence or presence of hypoxia. For hypoxic experiments the PAFs were exposed to either normoxia $\left(21 \% \mathrm{O}_{2}\right)$ or hypoxia $\left(1 \% \mathrm{O}_{2}\right)$ in a cell incubation chamber (Don Whitley Scientific Ltd., Shipley, UK) for the indicated time period.

Cell counting kit-8 (CCK8) assay. Cell viability and proliferation were assayed using CCK8 (Dojindo Molecular Technologies, Inc., Kumamoto, Japan) according to the manufacturer's protocol. PAFs were seeded in 96-well plates for $24 \mathrm{~h}$ and then starved for another $24 \mathrm{~h}$. The PAFs were subsequently treated with NVP-BEZ235 (10 nM), rapamycin (10 nM), LY294002 (10 $\mu \mathrm{M})$ or $0.1 \%$ dimethyl sulfoxide (Sigma-Aldrich; Merck KGaA, Darmstadt, Germany) as the control group $1 \mathrm{~h}$ prior to exposure to specific oxygen conditions for the indicated time periods. The PAFs were incubated with water-soluble tetrazolium salt- 8 for $2 \mathrm{~h}$ at $38^{\circ} \mathrm{C}$. The reaction product was then quantified by measuring the absorbance at $450 \mathrm{~nm}$ using a spectrophotometer.

Wound healing and Transwell assays. The PAF wound healing assay was performed according to a previously published protocol (31). Briefly, the cells were seeded at $5 \times 10^{6}$ cells/well in 6 -well cell culture plates. After $24 \mathrm{~h}$, three straight scratches were made in each well with the tip of a $200-\mu 1$ pipette. The wells were rinsed with PBS, which was replaced with DMEM media containing $0.5 \%$ FBS and the cells were incubated in normoxic or hypoxic conditions for the indicated time periods. Cell migration was captured at x 200 magnification using an optical microscope.

The Transwell migration assay was performed using Transwell inserts with an $8-\mu \mathrm{m}$ pore size (Corning Inc., Corning, NY, USA). The cells were trypsinized $(0.5 \%)$ for 1-2 min at room temperature, counted and then seeded into the upper insert at a density of $1 \times 10^{6}$ cells/well in DMEM with $1 \%$ serum. DMEM containing $10 \%$ FBS was added to the lower chamber. The cells were incubated at $37^{\circ} \mathrm{C}$ for the indicated time periods under normoxic or hypoxic conditions. The counting of the migrated cells was performed by eye, following fixation with $90 \%$ ethanol for $30 \mathrm{~min}$ and $0.1 \%$ crystal violet staining of the cells for $10 \mathrm{~min}$ at room temperature.

Immunofluorescence assay. An immunofluorescence assay was performed to detect the differentiation activity of the PAFs. The PAFs were fixed with $4 \%$ paraformaldehyde for $15 \mathrm{~min}$ at room temperature, and then blocked with $1 \%$ bovine serum albumin (cat. no. B2064; Sigma-Aldrich, Merck $\mathrm{KGaA}$ ) for $10 \mathrm{~min}$ at room temperature. The cells were incubated overnight at $4^{\circ} \mathrm{C}$ with antibodies directed against $\alpha$-smooth muscle actin ( $\alpha$-SMA; cat. no. ab5694; dilution 
1:200; Abcam, Cambridge, UK). Antibodies directed against GAPDH (cat. no. bs-2188R; dilution 1:500; Biosynthesis Biotechnology Co., Ltd., Beijing, China) were used as a reference. The cells were then washed with PBS for 15 min at room temperature. The cells were subsequently incubated with the relevant secondary antibodies, Alexa Fluor 488 immunoglobulin (Ig)G (cat. no. ZF-0511; dilution 1:500) or Alexa Fluor 594 IgG (cat. no. ZF-0513; dilution 1:500) (both OriGene Technologies, Inc., Beijing, China) for $60 \mathrm{~min}$ at room temperature. This was followed by washing with PBS for $15 \mathrm{~min}$. The cells in the target sections were incubated with DAPI (dilution 1:5,000; Sigma-Aldrich; Merck KGaA) for $10 \mathrm{~min}$ at room temperature in the dark. The results were observed through an immunofluorescence BX-60 microscope at x400 magnification (Olympus Corp., Tokyo, Japan). The fluorescence intensities of $\alpha$-SMA corresponding to GAPDH were analyzed using ImageJ 2x software (version 2.1.4.7; National Institutes of Health, Bethesda, MD, USA).

Western blot analysis. Following the indicated treatments, the PAFs were washed twice with ice-cold PBS and lysed on ice in $0.3 \mathrm{ml}$ lysis buffer (Tris $50 \mathrm{mM}$, pH 7.4; NaCl $150 \mathrm{mM}$; Triton X-100 1\%; EDTA $1 \mathrm{mM}$; and phenylmethane sulfonyl fluoride $2 \mathrm{mM}$ ) for $10 \mathrm{~min}$. The supernatants were collected and the total protein concentrations were determined using the BCA method (Pierce; Thermo Fisher Scientific, Inc.). Proteins (20 $\mu \mathrm{g} /$ lane) were separated by $10 \%$ SDS-PAGE and transferred onto nitrocellulose microporous membranes (Pall Life Sciences, Port Washington, NY, USA). The membranes were blocked with $5 \%$ skimmed milk powder for $30 \mathrm{~min}$ at room temperature. The membranes were then incubated with primary antibodies directed against $\mathrm{P} 110 \alpha$ (cat. no. 4249; dilution 1:1,000), p-Akt (Ser 473; cat. no. 4060; dilution 1:1,000), total Akt (cat. no. 9272; dilution 1:1,000), p70S6K (cat. no. 2708; dilution 1:1,000), p-p70S6K (Thr 389; cat. no. 9205; dilution 1:1,000) and $\beta$-actin (cat. no. 3700; dilution 1:3,000) (all Cell Signaling Technology, Inc.) and antibodies directed against proliferating cell nuclear antigen (PCNA; cat. no. bs2006R; dilution 1:500; Biosynthesis Biotechnology Co., Ltd.), $\alpha$-SMA (dilution 1:1,000) and GAPDH (dilution 1:500) overnight at $4^{\circ} \mathrm{C}$. The membranes were subsequently washed three times with PBS-Tween-20 for $10 \mathrm{~min}$ and then incubated with the the goat-anti-mouse (cat. no. bs2096G; dilution 1:5,000) or goat-anti-rabbit (cat. no. bs2095G; dilution 1:500) (both from Biosynthesis Biotechnology Co., Ltd.) secondary antibody for $1 \mathrm{~h}$ at room temperature. The blots were developed using an enhanced chemiluminescence Western Blotting Detection system with a ChemiDoc MP Imager (Bio-Rad Laboratories, Inc., Hercules, CA, USA). The densitometry values of the bands were measured using ImageJ 2x software (version 2.1.4.7).

Hypoxic rat model and grouping. Eight-week old, male SD rats were utilized for the in vivo experiments. The rats were randomly assigned to a normoxia group ( $\mathrm{N}$ group), hypoxia group (H group) or hypoxia plus NVP-BEZ235 group (HB group; $n=6 /$ group). The rats were maintained under specific conditions for 21 days. Hypobaric hypoxia was simulated in a laboratory-owned exclusive automatic hypobaric chamber, which mimicked the gaseous environment at 5,000 m above sea level with a fraction of inspired oxygen of 0.10 . Rats in the HB group were administered NVP-BEZ235 (in N-methyl-2-pyrrolidone/PEG300, 1/9 by volume; $35 \mathrm{mg} / \mathrm{kg}$ ) orally every other day from day 0 until they were euthanized on day 21 , whereas the rats in the $\mathrm{N}$ and $\mathrm{H}$ groups were administered $0.9 \%$ sodium chloride water as a control. The $\mathrm{N}$ group was placed in the same pathogen-free room as the $\mathrm{H}$ and $\mathrm{HB}$ group, but under normoxic conditions. Rats from all groups were kept under comparable living conditions $\left(25 \pm 2^{\circ} \mathrm{C}\right.$; $12 \mathrm{~h}$ light/dark cycles and humidity $40 \pm 10 \%$ ).

All rats were anesthetized using $50 \mathrm{mg} / \mathrm{kg}$ sodium pentobarbital, administered by intraperitoneal injection (5\% sodium pentobarbital; $1 \mathrm{ml} / \mathrm{kg}$ ) at the terminal point of the hypoxia exposure period. The right ventricular systolic pressure (RVSP) of the rats was detected via the right heart catheterization technique by connecting to a BL-420S biological function test system (Chengdu Techman Software Co., Ltd., Chengdu, China). Blood samples were taken from abdominal aorta of rats and tissue samples were taken from chest cavity of the rats. The ratio of the weight of the right ventricle to the left ventricle with the septum was used to assess the grade of right ventricular hypertrophy index (RVHI). The ratio of the weight of the right ventricle to the whole-body weight was used to assess the right ventricular weight/body weight index (RV/BW). The hematocrit (HCT) was evaluated by centrifugation of the blood samples at $112 \mathrm{x} \mathrm{g}$ at $4^{\circ} \mathrm{C}$ for $10 \mathrm{~min}$ using a microcentrifuge (Eppendorf, Hamburg, Germany).

Pathological staining assays. Lung specimens were obtained after blood samples were taken and saline perfusion was carried out from the abdominal aorta to reduce the blood cells in the lung tissue. The whole left and right lung specimens were then taken from chest cavity of the rats. These were then washed with 1X PBS, fixed with 4\% formaldehyde for $12 \mathrm{~h}$ at room temperature and embedded in paraffin wax prior to the staining of 5- $\mu \mathrm{m}$ sections. Hematoxylin and eosin (H\&E; cat. no. DH0006), Russell Movat (cat. no. DC0080) and Masson staining kits (cat. no. DC0033) were each purchased from Beijing Leagene Biotech Co., Ltd. (Beijing, China) and utilized according to the manufacturer's protocols. The stained specimens were viewed using an optical micoscope (DP71; Olympus Corp.).

Immunohistochemistry assay. Lung tissues (5- $\mu \mathrm{m}$ sections), prepared as described above, were tested by immunohistochemistry. An SPlink Detection kit (Biotin-Streptavidin HRP Detection Systems; cat. no. SP9000) and DAB Detection kit (cat. no. SP9000D) (both from OriGene Technologies, Inc.) were used for the immunohistochemistry assay, according to the manufacturer's protocol. The tissue sections were incubated overnight at $4^{\circ} \mathrm{C}$ with primary antibodies, which were directed against $\mathrm{p} 110 \alpha$ (dilution 1:200), p-Akt (dilution 1:200), Akt (dilution 1:200), p70S6K (dilution 1:200), fibronectin (cat. no. 4857R; dilution 1:400; Biosynthesis Biotechnology Co., Ltd.) and $\alpha$-SMA (dilution 1:400). The secondary antibodies contained in the SPlink Detection kits were then incubated with the sections for $1 \mathrm{~h}$ at room temperature. The stained specimens were viewed through an optical micoscope (DP71). Based on the pathology staining and immunohistochemistry results, the medial 
thickness (MT), medial cross-sectional area (MA), adventitial thickness (AT) and collagen deposition area percentage of the lung specimens of rats were measured and analyzed $(\mathrm{n}=15 ; 5$ pulmonary arterials in 3 rat per group).

Statistical analysis. All data are expressed as the mean \pm standard deviation. Differences between multiple groups were tested by one-way analysis of variance followed by Tukey's post hoc test and a two-tailed t-test was used for the comparison of two groups. $\mathrm{P}<0.05$ was considered to indicate a statistically significant difference. The plotting and statistical analysis of the data was performed using GraphPad Prism software, version 5 (GraphPad Software, Inc., La Jolla, CA, USA).

\section{Results}

Hypoxia promotes the proliferation, migration and differentiation of rat PAFs in vitro. The results of the CCK- 8 assay revealed that the proliferation of PAFs was significantly increased (14\%) under hypoxic conditions compared with normoxic conditions ( $\mathrm{P}=0.008)$ (Fig. 1A). Western blot analysis of the protein samples from cells in each group following culture for $24 \mathrm{~h}$ revealed that the PAFs had a significantly enhanced expression of PCNA (1.52 \pm 0.29 higher $)$ under hypoxic conditions compared with normoxic conditions $(\mathrm{P}=0.0032)$ (Fig. 1B and C).

In the wound healing assay, images captured after $12 \mathrm{~h}$ demonstrated the migration activity of the groups (Fig. 2A). The migration areas of each group were measured and the results revealed that hypoxia significantly promoted the migration activity of PAFs $1.31 \pm 0.21$-fold compared with that of PAFs cultured in normoxic conditions ( $\mathrm{P}=0.0018)$ (Fig. 2B). In the Transwell migration assay, the stained cell numbers revealed that hypoxia significantly increased the number of PAFs that migrated compared with the normoxia group $(\mathrm{P}=0.008)$ (Fig. 2C).

Optical microscopy images revealed that PAFs cultured under hypoxic conditions for 24 and $48 \mathrm{~h}$ changed their cellular morphology from long fusiform to irregular shapes (Fig. 3A). This was also demonstrated in the immunofluorescence images (Fig. 3B). $\alpha$-SMA and GAPDH were stained green and red, respectively, and the nuclei were stained blue with DAPI in the merged images. The fluorescence intensities of $\alpha$-SMA corresponding to GAPDH were analyzed using ImageJ software (Fig. 3C). These results revealed that hypoxia significantly increased $\alpha$-SMA expression compared with that in normoxic conditions $(\mathrm{P}<0.001)$. Additionally, western blot analysis also indicated that hypoxia significantly elevated the expression of $\alpha$-SMA compared with that in the normoxia group ( $\mathrm{P}=0.006)$ (Fig. 3D and $\mathrm{E})$.

Hypoxia upregulates the PI3K/Akt/p70S6K signaling pathway in PAFs in vitro. PAFs were cultured under hypoxia for $24 \mathrm{~h}$ and western blot analysis (Fig. 4A) was conducted. The results revealed that the expression levels of p110 $\alpha$ (Fig. 4B), p-Akt (Fig. 4C) and p-p70S6K (Fig. 4D) were significantly increased in the hypoxia group compared with the normoxia group $(\mathrm{P}<0.01)$.

The dual PI3K/mTOR inhibitor NVP-BEZ235 was utilized to inhibit the PI3K/mTOR signaling pathway. To confirm the
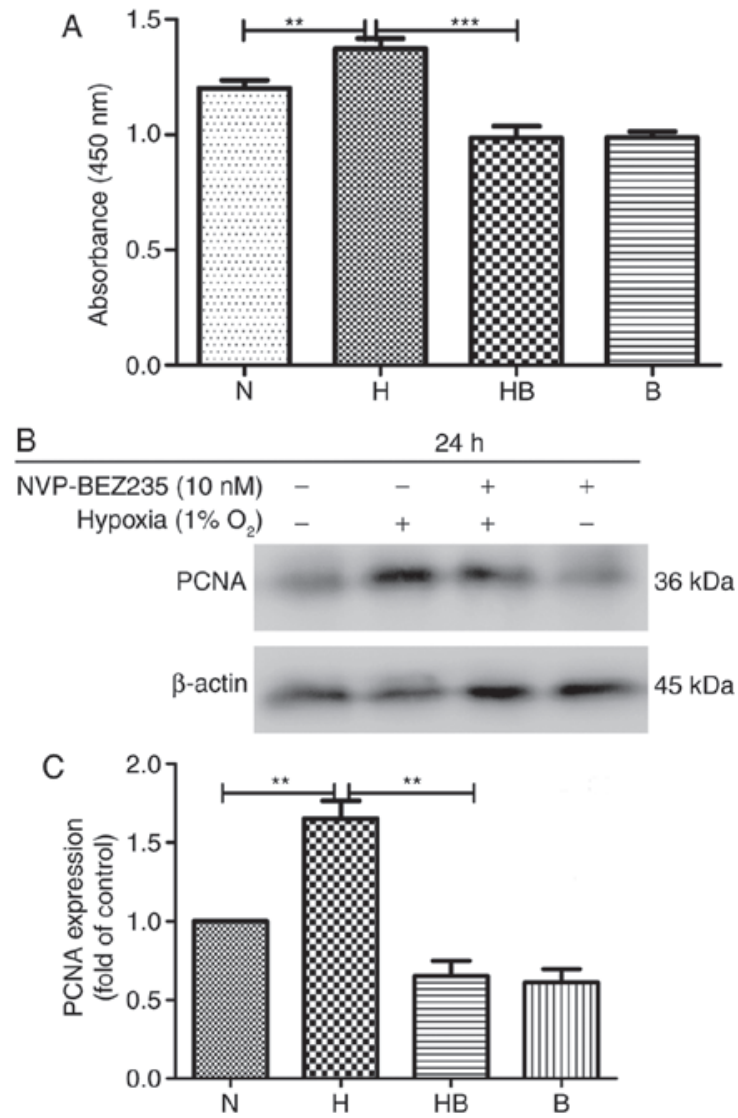

Figure 1. Hypoxia-induces the proliferation of PAFs in vitro. (A) The proliferation of PAFs was measured using a cell counting kit- 8 assay following treatment as indicated for $24 \mathrm{~h}(\mathrm{n}=8)$. (B) Western blot analysis of PCNA expression in all PAF groups following treatment for $24 \mathrm{~h}(\mathrm{n}=3)$. (C) PCNA expression analysis of the western blot analyses. N, normoxia; $\mathrm{H}$, hypoxia; HB, hypoxia with NVP-BEZ235; B, NVP-BEZ235; PAFs, pulmonary arterial fibroblasts; $\mathrm{PCNA}$, proliferating cell nuclear antigen. ${ }^{* *} \mathrm{P}<0.01$ and **** $\mathrm{P}<0.001$

effectiveness of NVP-BEZ235, PAFs were cultured for $1 \mathrm{~h}$ with NVP-BEZ235 at a range of concentrations $(2.5-50 \mathrm{nM})$ and the expression levels of P110 $\alpha$, p-Akt and p-p70S6K were measured using western blotting (Fig. 5A-D). The results demonstrate that low concentrations of NVP-BEZ235 $(1-5 \mathrm{nM})$ significantly inhibited the expression of $\mathrm{p} 110 \alpha(1 \mathrm{nM}$; $\mathrm{P}=0.0021)$, p-Akt (5 nM; $\mathrm{P}=0.0043)$ and p-p70S6K (5 nM; $\mathrm{P}=0.0065)$. PAFs were also treated with $10 \mathrm{nM}$ NVP-BEZ235 for varying time periods $(30-150 \mathrm{~min}$; Fig. $5 \mathrm{E}-\mathrm{H})$ and the expression levels of $\mathrm{P} 110 \alpha, \mathrm{p}$-Akt and p-p70S6K were measured using western blotting. The results reveal that the expression of $\mathrm{p} 110 \alpha(\mathrm{P}<0.01)$ was significantly inhibited at $30 \mathrm{~min}$ and the expression levels of $\mathrm{p}-\mathrm{Akt}(\mathrm{P}=0.0013)$ and p-p70S6K $(P<0.001)$ were significantly inhibited at $60 \mathrm{~min}$. No significant differences were identified in the expression of Akt and p70S6K following treatment with NVP-BEZ235 (data not shown).

Hypoxia-induced proliferation, migration and differentiation are reduced following inhibition of the PI3K/Akt/p70S6K signaling pathway. The proliferation of PAFs under hypoxic conditions was significantly reduced following the inhibition of the PI3K/mTOR signaling pathway by NVP-BEZ235 $(\mathrm{P}<0.001)($ Fig. 1A). The expression of PCNA in rat PAFs 
A
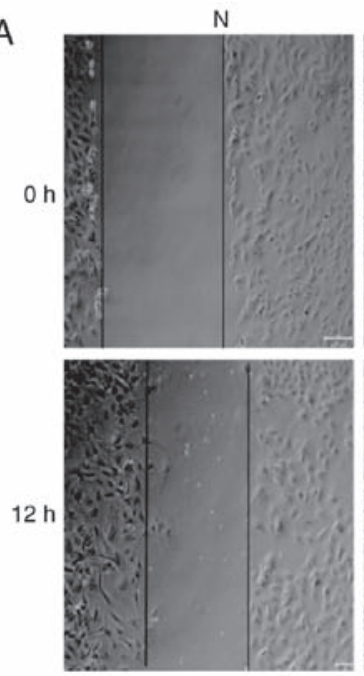

B

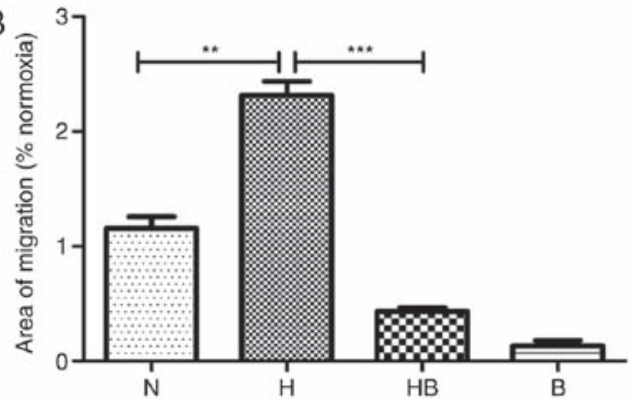

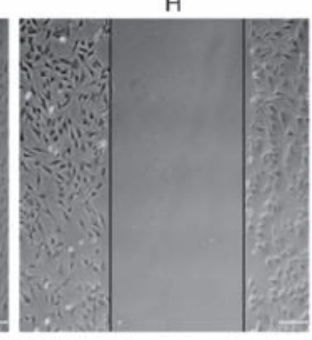

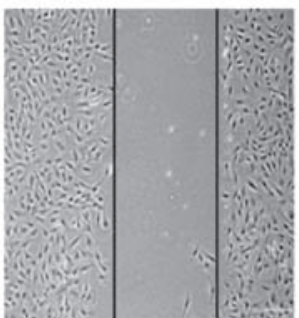

$\mathrm{HB}$
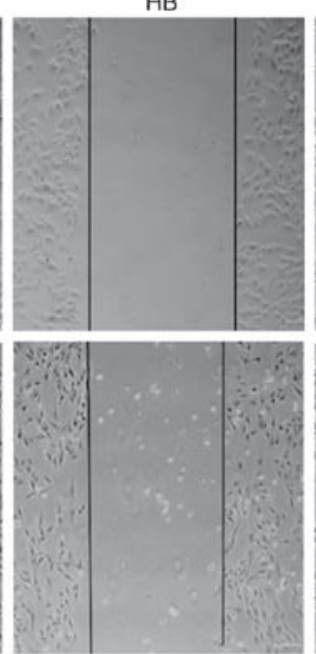

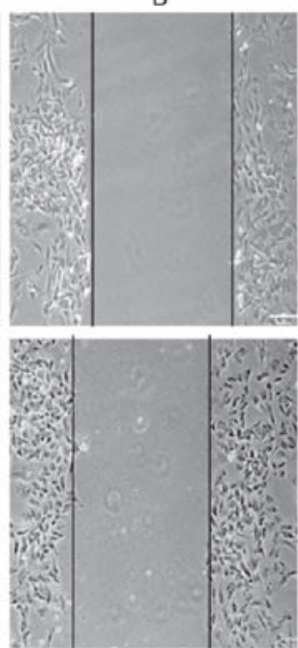

C

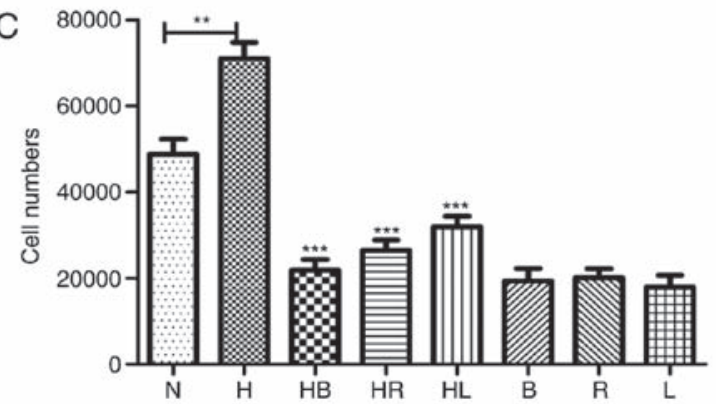

Figure 2. Hypoxia induces the migration of PAFs in vitro. (A) Results of the scratch assay in PAFs following $12 \mathrm{~h}$ of treatment ( $\mathrm{n}=3$ ). (B) Migration area results of the scratch assay $(n=6)$. (C) Cell numbers in the Transwell migration assay determined by cell counting following staining ( $\mathrm{n}=6$ ). PAFs, pulmonary arterial fibroblasts; N, normoxia; H, hypoxia; HB, hypoxia with NVP-BEZ235; HR, hypoxia with rapamycin; HL, hypoxia with LY294002; B, NVP-BEZ235; $\mathrm{R}$, rapamycin; L, LY294002. ${ }^{* *} \mathrm{P}<0.01$ and ${ }^{* * *} \mathrm{P}<0.001$.

was also significantly downregulated by pretreatment with NVP-BEZ235 prior to hypoxia, compared with that in the hypoxia group $(\mathrm{P}=0.0041)$ (Fig. $1 \mathrm{~B}$ and $\mathrm{C})$.

In other experiments, PAFs were incubated with different concentrations of NVP-BEZ235 $(0,1,5,10,20$ and $80 \mathrm{nM})$ for $24 \mathrm{~h}$, or they were incubated with $10 \mathrm{nM}$ NVP-BEZ235 for increasing periods of time $(0,6,12,24$ and $48 \mathrm{~h})$. The results indicated that stronger and prolonged inhibition of the PI3K/mTOR signaling pathway by NVP-BEZ235 influenced the proliferative activity of PAFs under normoxic and hypoxic conditions (Fig. 6A and B).

Additionally, the wound healing assay revealed that NVP-BEZ235 significantly reduced the hypoxia-induced migratory activity of PAFs compared with that in the hypoxia group $(\mathrm{P}<0.001)$ (Fig. 2B). Furthermore, the Transwell assay revealed that rapamycin, LY294002 and NVP-BEZ235 significantly reduced the migration of rat PAFs under hypoxic conditions $(\mathrm{P}<0.001)$ (Fig. $2 \mathrm{C})$. In other Transwell experiments, PAFs were incubated with increasing concentrations of NVP-BEZ235 $(0,5,10,20$ and $40 \mathrm{nM})$ for $24 \mathrm{~h}$, or were incubated with $10 \mathrm{nM}$ NVP-BEZ235 for increasing periods of time $(0,6,12$ and $24 \mathrm{~h})$. The results also indicated that inhibition of the PI3K/mTOR signaling pathway with NVP-BEZ235 significantly reduced the migratory activity of PAFs under hypoxia in a dose dependent manner (Fig. 6C) and this significant reduction in migration was observed at all time periods tested $(\mathrm{P}<0.05)$ (Fig. 6D).
NVP-BEZ235 pretreatment significantly decreased the hypoxia-induced elevation of $\alpha$-SMA expression in the immunofluorescence assay $(\mathrm{P}<0.001)$ (Fig. 3C). Western blot analysis confirmed that NVP-BEZ235 attenuated the expression of $\alpha$-SMA in PAFs cultured under hypoxic conditions for $48 \mathrm{~h}(\mathrm{P}=0.017)$ (Fig. 3E). However, no significant difference in a-SMA expression was identified in PAFs cultured under hypoxic conditions following pretreatment with LY294002 (Fig. 3D and E). In addition, it was observed that treatment of PAFs with $\geq 10 \mathrm{nM}$ concentrations of NVP-BEZ235 had a significant inhibitory effect on the expression of $\alpha$-SMA compared with the $0 \mathrm{nM}$ control group $(\mathrm{P}<0.05)$ (Fig. 6E and F). When PAFs were treated with NVP-BEZ235 at $10 \mathrm{nM}$ for increasing time periods $(1,6,12$, 24 and $48 \mathrm{~h}$ ), a significant reduction in $\alpha$-SMA expression was observed from $6 \mathrm{~h}(\mathrm{P}<0.05)$ (Fig. 6G and $\mathrm{H})$.

Hypoxia contributes to the pulmonary vascular remodeling of hypoxic rats in vivo. The RVSP in the $\mathrm{H}$ group $(49.76 \pm 1.31 \mathrm{mmHg})$ was significantly elevated compared with that in the $\mathrm{N}$ group $(27.85 \pm 0.42 \mathrm{mmHg}$; $\mathrm{P}<0.001)$ (Fig. 7A). The RVHI reflects the right ventricular remodeling caused by pulmonary arterial pressure elevation, and the RVHI in the $\mathrm{H}$ group $(0.48 \pm 0.03)$ was significantly higher than that in the $\mathrm{N}$ group $(0.27 \pm 0.01 ; \mathrm{P}=0.0032)$ (Fig. $7 \mathrm{~B})$. The HCT of the H group $(80.38 \pm 1.49 \%)$ was significantly higher than that of the $\mathrm{N}$ group $(34.96 \pm 1.40 \%$; $\mathrm{P}<0.0010$ (Fig. 7C). 

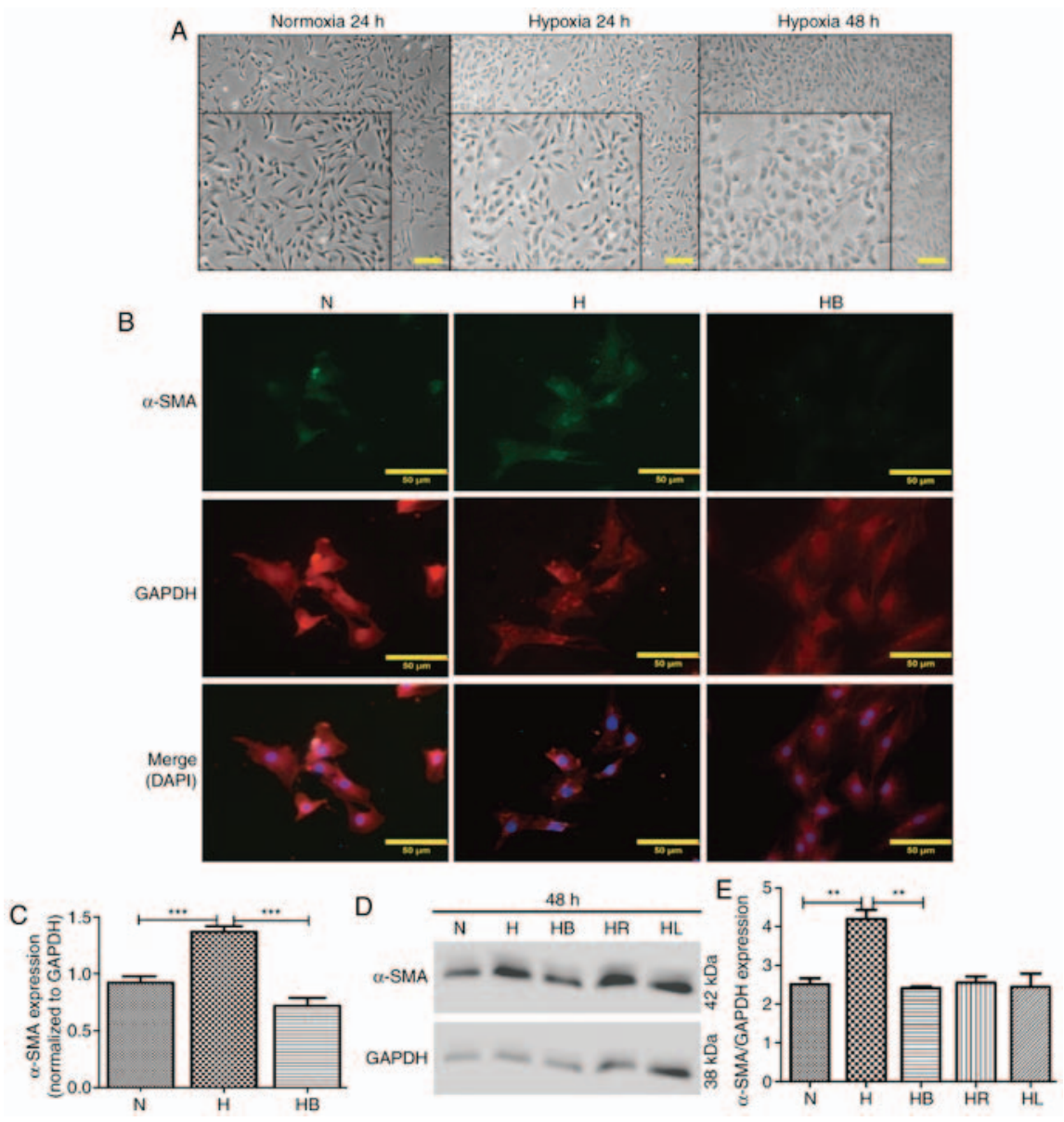

Figure 3. Hypoxia-induced differentiation of PAFs requires activation of the PI3K/Akt/p70S6K signaling pathway. (A) Cellular morphology of PAFs under normoxic and hypoxic conditions. The images were captured using an optical microscope (magnification, main images, $\mathrm{x} 200$, enlarged images, $\mathrm{x} 450$ ). A portion of the photographs was enlarged and displayed at the bottom left corner. (B) PAFs were treated as indicated for $24 \mathrm{~h}$, then subjected to immunofluorescence staining. $\alpha$-SMA was stained green, GAPDH was stained red and the nuclei were stained blue by DAPI in the merged images. (C) The expression of $\alpha$-SMA in the immunofluorescence photographs was examined $(n=3)$. (D) Western blot analysis was performed to evaluate the expression of $\alpha$-SMA and GAPDH in the PAFs. (E) The expression of $\alpha$-SMA in the western blot was quantified. PAFs, pulmonary arterial fibroblasts; N, normoxia; H, hypoxia; HB, hypoxia with NVP-BEZ235; HR, hypoxia with rapamycin; HL, hypoxia with LY294002; $\alpha$-SMA, $\alpha$-smooth muscle actin. ${ }^{* *} \mathrm{P}<0.01$ and ${ }^{* * *} \mathrm{P}<0.001$.
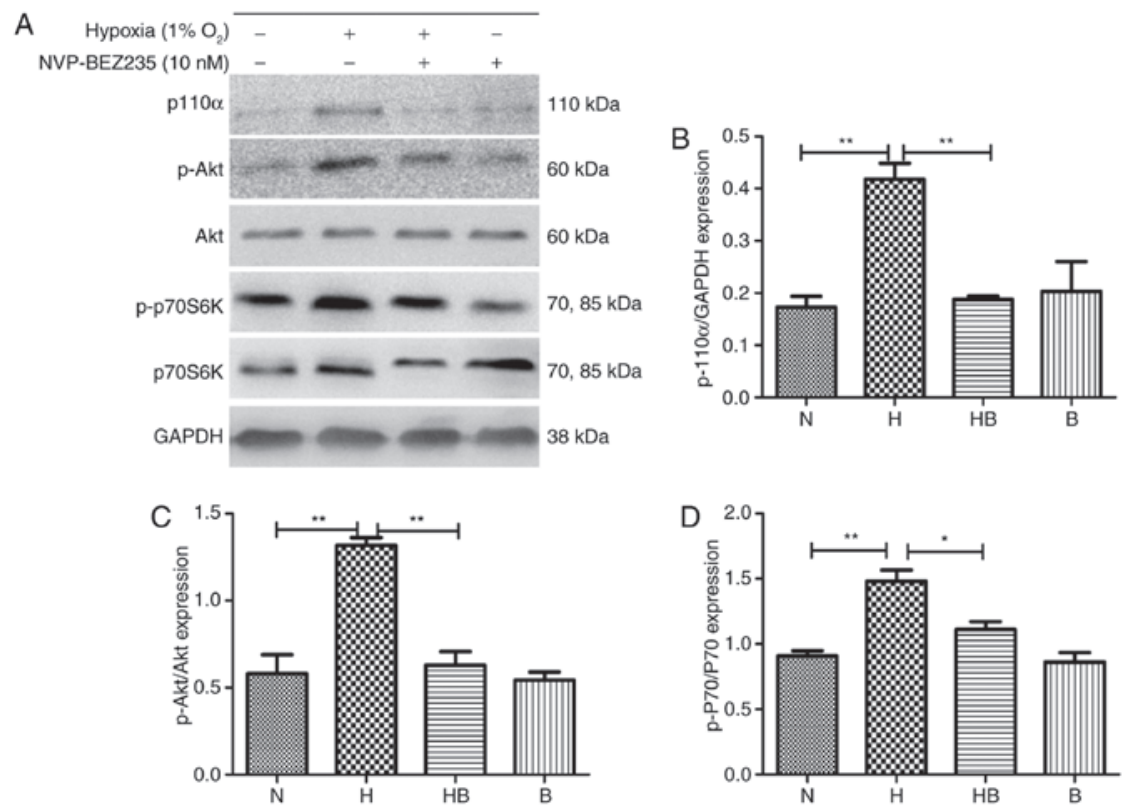

Figure 4. Hypoxia upregulates the PI3K/Akt/p70S6K signaling pathway in PAFs. (A) Western blot analysis of the indicated proteins in PAFs following treatment with NVP-BEZ235 and hypoxia as indicated for $24 \mathrm{~h}$. Quantification of (B) p110 $\alpha$, (C) p-Akt and (D) p-p70S6K expression in the western blot assay (n=3). PAFs, pulmonary arterial fibroblasts; PI3K, phosphatidylinositol-3-kinase; Akt, protein kinase B; p70S6K, p70 ribosomal protein S6 kinase; p, phosphorylated; $\mathrm{N}$, normoxia; H, hypoxia; HB, hypoxia with NVP-BEZ235; B, NVP-BEZ235. ${ }^{*} \mathrm{P}<0.05$ and ${ }^{* *} \mathrm{P}<0.01$. 

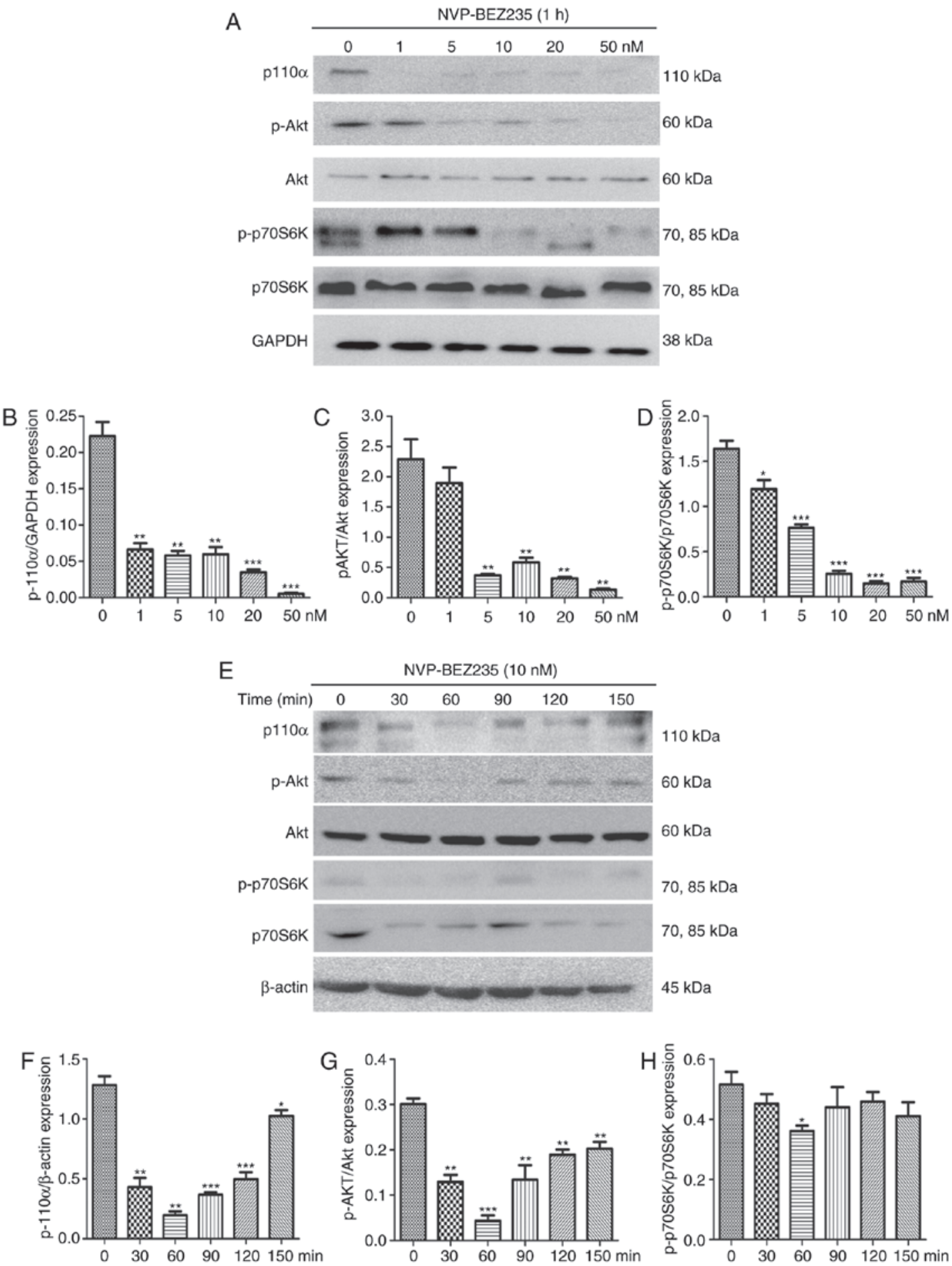

Figure 5. NVP-BEZ235 inhibits the PI3K/Akt/p70S6K signaling pathway in rat PAFs. (A) Western blot analysis of the dose response of PAFs treated with NVP-BEZ235 for $24 \mathrm{~h}$. Quantitative analysis of (B) p110 $\alpha$, (C) p-Akt and (D) p-p70S6K expression in the western blot assay (n=3). (E) Western blot analysis of the response of PAFs treated with NVP-BEZ235 (10 nM) for increasing time periods. Quantitative analysis of $(\mathrm{F}) \mathrm{p} 110 \alpha,(\mathrm{G}) \mathrm{p}-\mathrm{Akt}$ and $(\mathrm{H}) \mathrm{p}-\mathrm{p} 70 \mathrm{~S} 6 \mathrm{~K}$ expression in the western blot assay ( $\mathrm{n}=3$ ). PAFs, pulmonary arterial fibroblasts; PI3K, phosphatidylinositol-3-kinase; Akt, protein kinase B; p70S6K, p70 ribosomal protein S6 kinase; $\mathrm{p}$, phosphorylated. ${ }^{*} \mathrm{P}<0.05,{ }^{* *} \mathrm{P}<0.01$ and ${ }^{* * *} \mathrm{P}<0.001$.

The RV/BW data revealed that the RV/BW of the $\mathrm{H}$ group $(1.63 \pm 0.07 \mathrm{mg} / \mathrm{g})$ was significantly higher than that of the $\mathrm{N}$ group $(0.69 \pm 0.02 \mathrm{mg} / \mathrm{g} ; \mathrm{P}=0.0002)$ (Fig. 7D). H\&E staining of the rat lung tissues presented clear views of the arteries (diameter $<200 \mu \mathrm{m}$ ) (Fig. 8A). Russell Movat staining and Masson staining was conducted to reveal the collagen deposition around the pulmonary vessels. It was observed that the $\mathrm{H}$ group had an increased thickening of the pulmonary vessel walls and small vessel lumens compared with the $\mathrm{N}$ group. The same trend was observed for the collagen deposition area around the vessels. Immunohistochemistry results revealed that the $\mathrm{H}$ group had increased expression of fibronectin and $\alpha$-SMA compared with the other groups. The perimeter of the lumen and $>5$ small pulmonary vascular vessels in a minimum of 3 rats per group were measured. The MT, MA, AT and collagen deposition area were calculated to assess the 

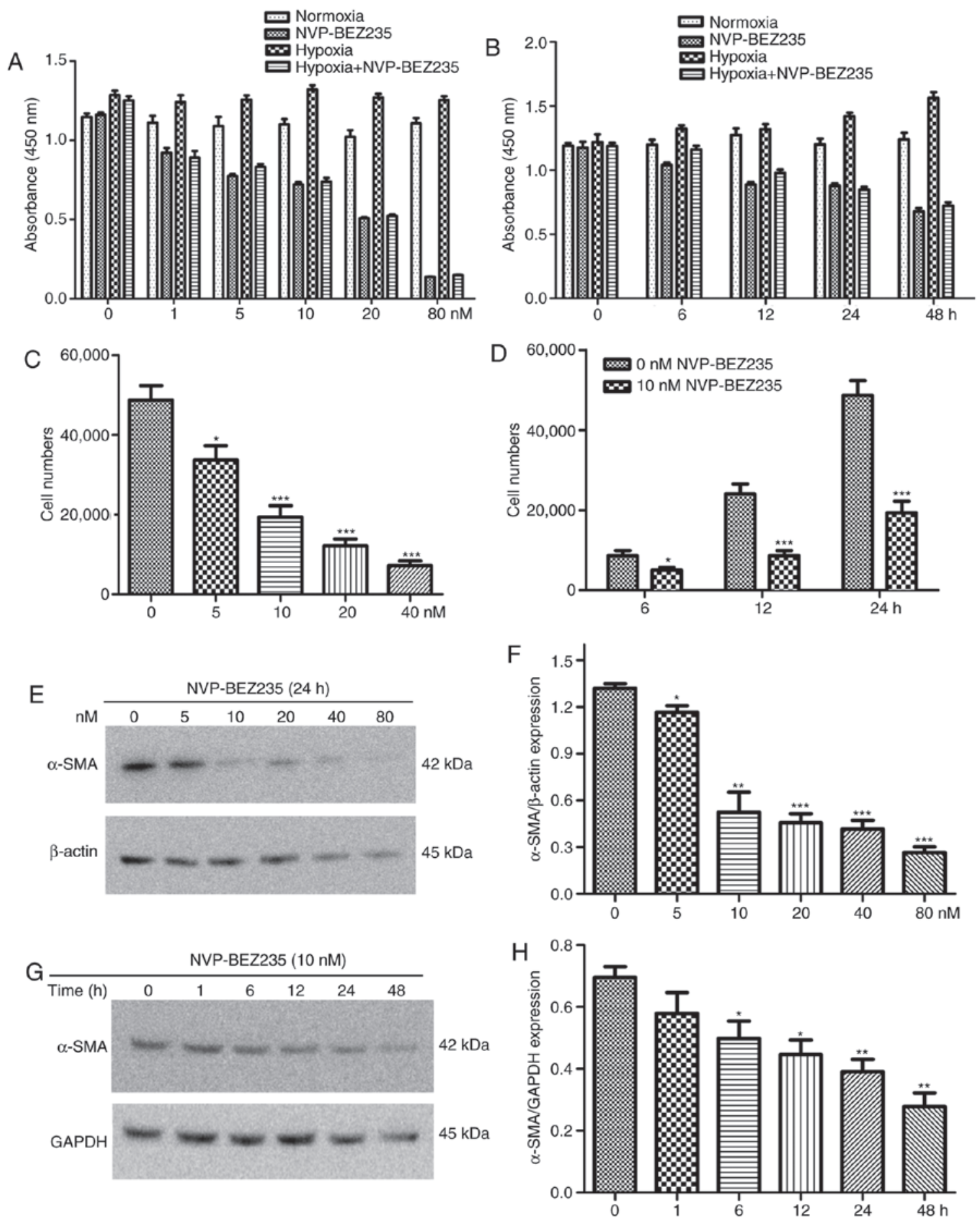

Figure 6. NVP-BEZ235 inhibits the hypoxia-induced proliferation, migration and differentiation of rat PAFs in a dose- and time-dependent manner. (A) The proliferation results of PAFs treated with increasing concentrations of NVP-BEZ235 as measured by a CCK-8 assay ( $\mathrm{n}=8$ ). (B) The proliferation results of PAFs treated with $10 \mathrm{nM}$ NVP-BEZ235 for increasing periods of time as measured by a CCK-8 assay $(\mathrm{n}=8)$. The cell migration results of PAFs treated with (C) increasing concentrations of NVP-BEZ235 and (D) $10 \mathrm{nM}$ NVP-BEZ235 for increasing time periods as measured by a Transwell assay (n=8). (E) Western blot analysis of the expression of $\alpha$-SMA and $\beta$-actin in PAFs treated with increasing concentrations of NVP-BEZ235 for $24 \mathrm{~h}$. (F) Quantitative analysis of the $\alpha$-SMA expression observed in the western blot analyses $(\mathrm{n}=3)$. $(\mathrm{G})$ Western blot analysis of the expression of $\alpha$-SMA and GAPDH in PAFs treated with $10 \mathrm{nM}$ NVP-BEZ235 for increasing time periods. (H) Quantitative analysis of the $\alpha$-SMA expression observed in the western blot analyses ( $\mathrm{n}=3$ ). PAFs, pulmonary arterial fibroblasts; CCK-8, cell counting kit-8; $\alpha$-SMA, $\alpha$-smooth muscle actin. ${ }^{*} \mathrm{P}<0.05,{ }^{* *} \mathrm{P}<0.01$ and ${ }^{* * *} \mathrm{P}<0.001$.

severity of the pulmonary vascular remodeling (Fig. 8B-E). The $\mathrm{H}$ group had a significantly higher MT, MA, AT and collagen deposition area $(41.64 \pm 1.54,65.50 \pm 1.50,64.33 \pm 7.02$ and $64.00 \pm 7.81 \%$, respectively) compared with the $\mathrm{N}$ group $(28.65 \pm 1.91, \mathrm{P}<0.001 ; 48.67 \pm 2.68, \mathrm{P}<0.001 ; 26.00 \pm 5.66$, $\mathrm{P}=0.0018 ; 9.80 \pm 2.95 \%, \mathrm{P}<0.001$, respectively) (Fig. 8B-E).
The PI3K/Akt/p70S6K signaling pathway is upregulated in the pulmonary vessels of hypoxic rats. Immunohistochemistry results of lung tissues from the HPH rats revealed that hypoxia markedly increased the expression of p110 $\alpha$, p-Akt and p70S6K around the adventitious small pulmonary vasculature in vivo. Pretreatment with NVP-BEZ235 clearly inhibited 

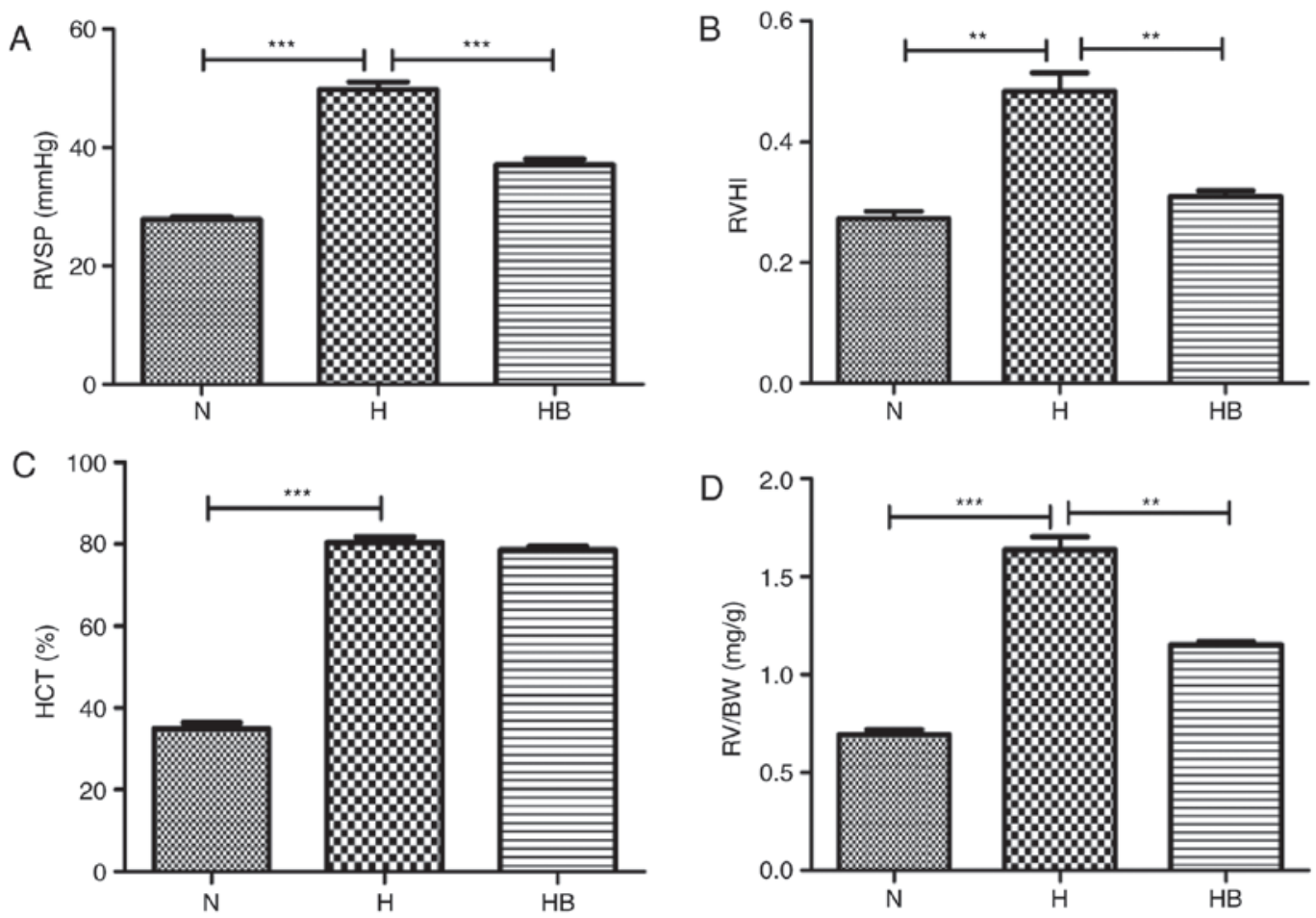

Figure 7. The PI3K/Akt/p70S6K signaling pathway contributes to the physiological process of hypoxia in rats. (A) RVSP, (B) RVHI, (C) HCT and (D) RV/BW results from rats in different groups. RVSP, right ventricular systolic pressure; RVHI, right ventricular hypertrophy index; HCT, hematocrit; RV/BW, right ventricular/body weight ratio; $\mathrm{N}$, normoxia; $\mathrm{H}$, hypoxia; $\mathrm{HB}$, hypoxia plus NVP-BEZ235. ${ }^{* *} \mathrm{P}<0.01$ and ${ }^{* * *} \mathrm{P}<0.001$.

the hypoxia-induced elevation of p110 $\alpha$, p-Akt and p70S6K expression in vivo (Fig. 9).

NVP-BEZ235 attenuates hypoxia-induced pulmonary vascular remodeling. The RVSP of the HB group $(37.10 \pm 0.91 \mathrm{mmHg})$ was significantly lower than that of the $\mathrm{H}$ group $(\mathrm{P}<0.001)$ (Fig. 7A). The RVHI of the HB group $(0.31 \pm 0.01)$ was significantly lower than that of the H group ( $\mathrm{P}=0.006$ ) (Fig. 7B). The RV/BW ratio of the HB group $(1.15 \pm 0.02 \mathrm{mg} / \mathrm{g})$ was also significantly lower than that of the $\mathrm{H}$ group ( $\mathrm{P}=0.0021)$ (Fig. 7D). No significant difference was identified in the HCT of the HB group $(78.57 \pm 0.87 \%)$ compared with the $\mathrm{H}$ group (Fig. $7 \mathrm{C}$ ). These results indicate that the HB group had less thickening of the vascular walls compared with the $\mathrm{H}$ group. The immunohistochemistry staining revealed that pretreatment with NVP-BEZ235 (HB group) significantly attenuated the hypoxia-induced MT, MA, AT and collagen deposition area $(32.17 \pm 1.75,53.42 \pm 2.34$, $41.33 \pm 4.04$ and $25.60 \pm 5.27$, respectively) compared with the $\mathrm{H}$ group $(\mathrm{P}<0.001, \mathrm{P}=0.0003, \mathrm{P}=0.0008$ and $\mathrm{P}<0.001$, respectively) (Fig. 8B-E).

\section{Discussion}

The in vitro experiments in the present study demonstrated that a hypoxic environment promotes the proliferation, migration and differentiation of rat PAFs. To investigate the possible mechanisms underlying this enhanced proliferation, migration and differentiation, the present study focused on the PI3K/Akt/p70S6K signaling pathway. PI3K may be activated by growth factors and hormones, and in turn coordinates the cell cycle, and the growth, migration and survival of cells. p70S6K is activated by positive signaling from mTOR, and serves a critical role in the regulation of migration where it acts in the process of polymerization $(32,33)$. Akt promotes cell survival by inhibiting apoptosis, and is also associated with the regulation of the cell cycle (32-36). Previous studies have indicated that the $\mathrm{PI} 3 \mathrm{~K} / \mathrm{Akt} / \mathrm{p} 70 \mathrm{~S} 6 \mathrm{~K}$ signaling pathway serves an essential role in the development and functions of blood vessels (37). The authors of the present study hypothesized that the PI3K/Akt/p70S6K signaling pathway may be involved in the hypoxia-induced proliferation, migration and differentiation behaviors of rat PAFs, and could be associated with hypoxia-induced pulmonary vascular remodeling in hypoxic rats.

The results of the present study support this hypothesis. The in vitro experiments demonstrated that the PI3K/Akt/p70S6K signaling pathway in rat PAFs was significantly activated by hypoxia $\left(1 \% \mathrm{O}_{2}\right)$, although previous studies have reported that hypoxia triggers the PI3K/mTOR signaling pathway in a cell-specific manner, different kinds of cells could show quite different changes of the PI3K/mTOR signaling pathway under hypoxia. Consistent with the previous studies, the present study demonstrated that hypoxia upregulates the PI3K/mTOR signaling pathway of PAFs $(10,24,29)$. In the present study, rat PAFs exhibited distinct capabilities to proliferate, migrate and differentiate in response to hypoxia without exogenous growth factors, which was consistent with the findings of previous studies $(28,37)$. It was subsequently considered that the PI3K/Akt/p70S6K signaling pathway may be involved in the hypoxia-induced proliferation, migration and differentiation behaviors of rat PAFs. Various inhibitors of the PI3K/Akt/p70S6K signaling pathway were used to investigate this, and it was demonstrated that the hypoxia-induced proliferation, migration and differentiation were notably reduced when the inhibitors were administered. This strengthened the 

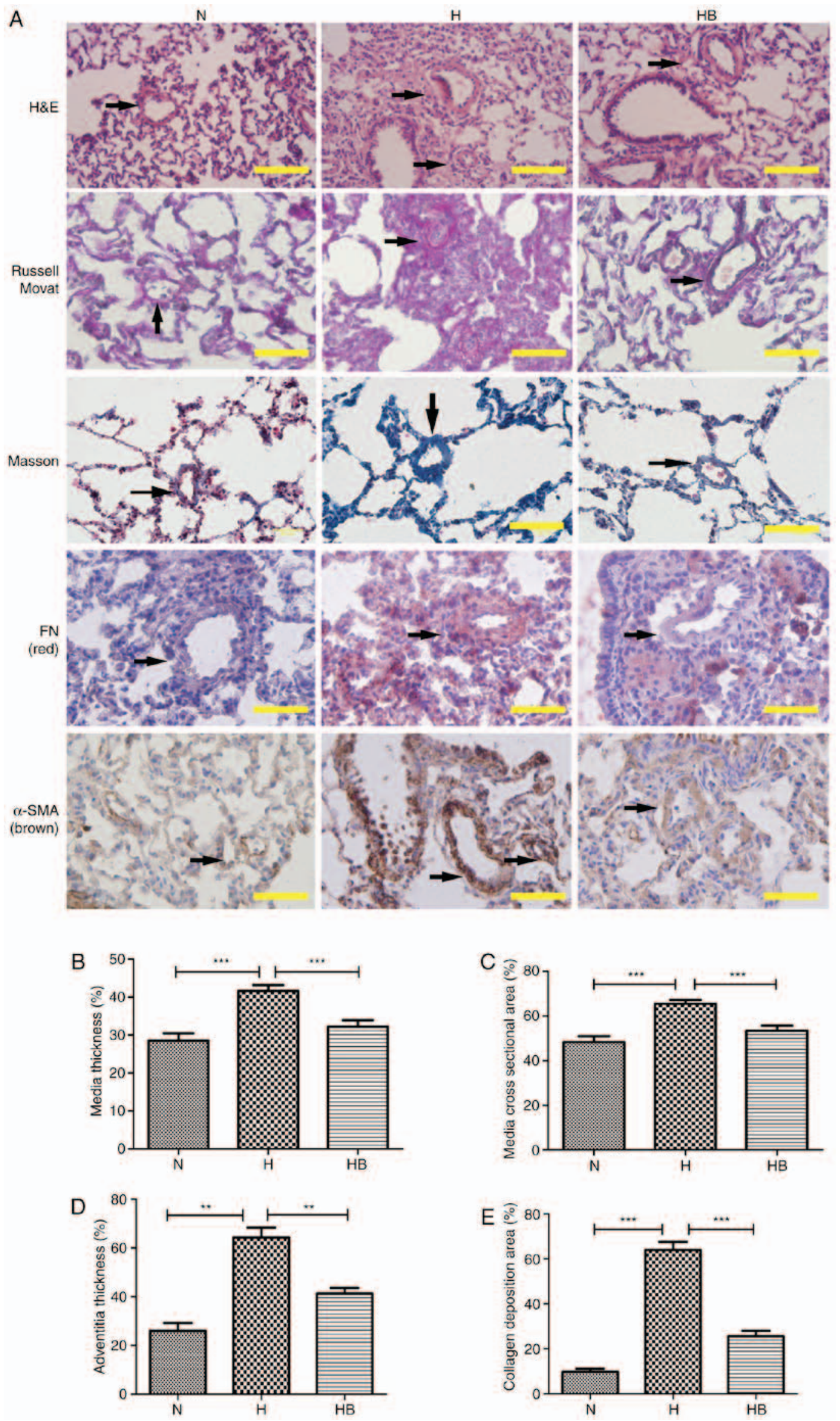

Figure 8. The PI3K/Akt/p70S6K signaling pathway contributes to the pulmonary vascular remodeling of hypoxic rats. (A) H\&E, Russell Movat, Masson and immunohistochemical staining of FN and $\alpha$-SMA in lung tissue isolated from rats in the different groups. The black arrows indicate the pulmonary vessels. The (B) medial thickness, (C) medial cross-sectional area, (D) adventitial thickness and (E) collagen deposition area were calculated. A total of 3 rats were randomly selected from each group and at least five pulmonary arterials of each rat were measured. Scale bar, $100 \mu \mathrm{m}$. N, normoxia; H, hypoxia; HB, hypoxia with NVP-BEZ235; FN, fibronectin; H\&E, hematoxylin and eosin. ${ }^{* *} \mathrm{P}<0.01$ and ${ }^{* * *} \mathrm{P}<0.001$. 


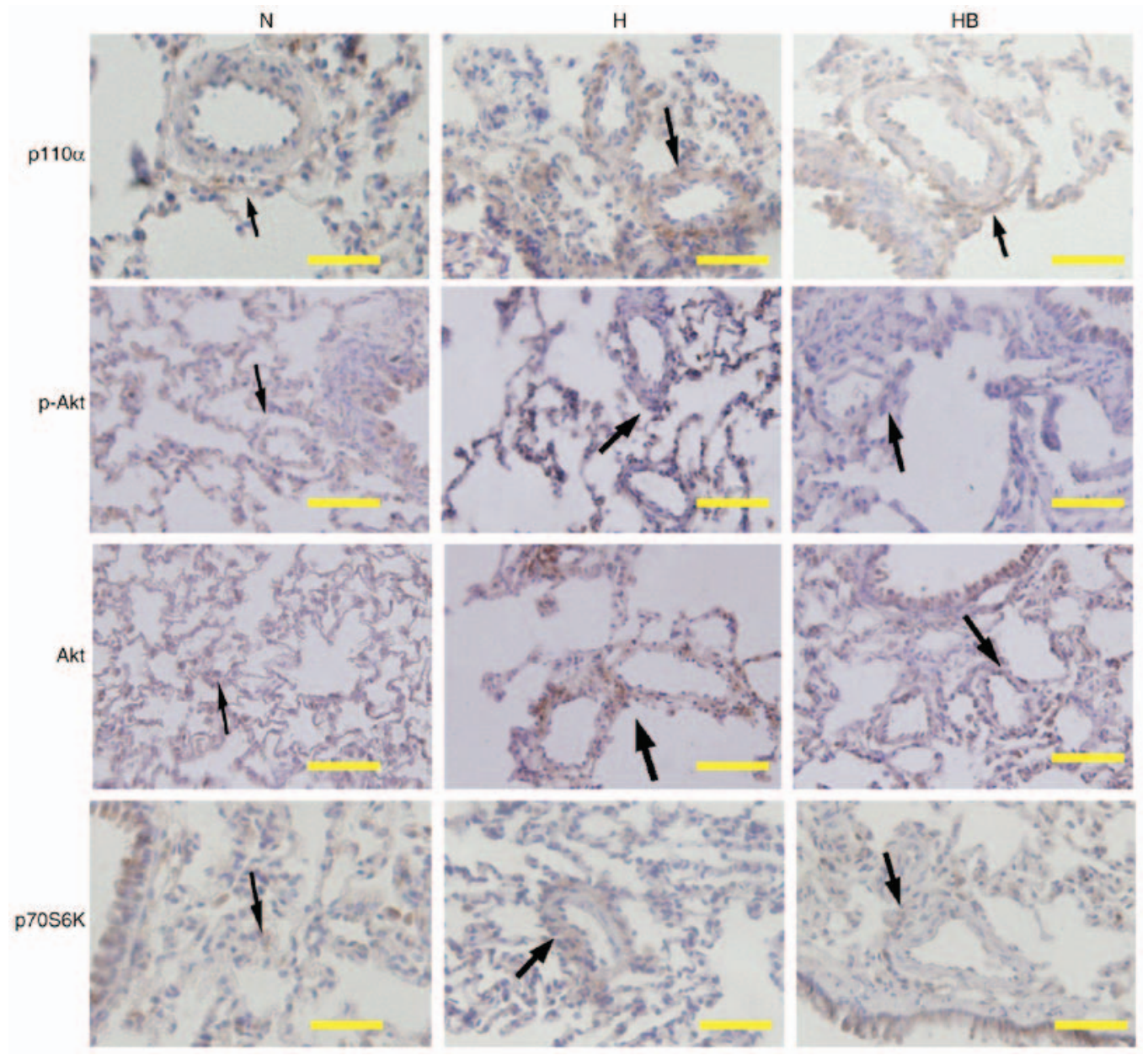

Figure 9. The PI3K/Akt/p70S6K signaling pathway is upregulated in the pulmonary vessels of rats following hypoxia. Immunohistochemistry results of p110 $\alpha$, p-Akt and p70S6K in the pulmonary vessels of rats. The black arrows identify the positively stained areas. Scale bar, $100 \mu \mathrm{m}$. N, normoxia; H, hypoxia; HB, hypoxia with NVP-BEZ235; Akt, protein kinase B; p, phosphorylated; p70S6K, p70 ribosomal protein S6 kinase.

evidence that the PI3K/Akt/p70S6K signaling pathway was necessary for the changes in the hypoxia-induced proliferation, migration and differentiation in rat PAFs that were observed.

The results of the in vivo experiments revealed that hypoxia induced pulmonary vascular remodeling with the elevation of RVSP, RVHI and RV/BW, and the promotion of MA, MT, AT and the collagen deposition area. This suggests that hypoxia induced pulmonary vascular remodeling. The results also demonstrated that the expression of p110 $\alpha$, p-Akt and p70S6K was significantly increased and the PI3K/Akt/p70S6K signaling pathway was activated during the hypoxic exposure period. To examine if the activation of the PI3K/Akt/p70S6K signaling pathway was necessary for the development of hypoxic pulmonary vascular remodeling, NVP-BEZ235 was used to block the PI3K/Akt/p70S6K signaling pathway and the results indicated that the hypoxia-induced pulmonary vascular remodeling was attenuated. The results of the in vivo experiments indicate the important roles of the PI3K/Akt/p70S6K signaling pathway in the hypoxia-induced pulmonary vascular remodeling process of hypoxic rats.

The results of the present study also indicated that NVP-BEZ235 significantly inhibited Akt signaling, which is likely to be due to the inhibition of upstream PI3K and its downstream feedback as the agent did not inhibit Akt directly $(38,39)$. The HCT results suggest that erythrocyte production under hypoxia is not directly regulated by the
PI3K/mTOR signaling pathway; further research is required to explore the detailed mechanisms behind this $(40,41)$.

In conclusion, the findings of the present study suggest that the PI3K/Akt/p70S6K signaling pathway is essential for hypoxia-induced PAF proliferation, migration and differentiation, as well as for pulmonary vascular remodeling in hypoxic rats. NVP-BEZ235 is able to attenuate the hypoxia-induced pulmonary vascular remodeling of hypoxic rats in vivo, which suggests it may be a potential intervention target for HPH.

\section{Acknowledgements}

The authors would like to thank Professor Junbao Du and Professor Hongfang Jin (Pediatric Department of Peking University First Hospital, Beijing, China) and Dr Yong Wang and Dr Lei Pan (Department of Geriatrics, Beijing Shijitan Hospital of Capital Medicine University, Beijing, China) for their technical assistance, and the Beijing Shijitan Hospital of Capital Medicine University (Beijing, China) for access to its hypoxia laboratory. The present study was supported by the National Natural Science Foundation of China (grant no. 81270114).

\section{Competing interests}

The authors declare that they have no competing interests. 


\section{References}

1. Oudiz RJ: Classification of pulmonary hypertension. Cardiol Clin 34: 359-361, 2016.

2. Poor HD, Girgis R and Studer SM: World Health Organization Group III pulmonary hypertension. Prog Cardiovasc Dis 55: 119-127, 2012

3. Nathan SD and Hassoun PM: Pulmonary hypertension due to lung disease and/or hypoxia. Clin Chest Med 34: 695-705, 2013.

4. Veit F, Pak O, Brandes RP and Weissmann N: Hypoxia-dependent reactive oxygen species signaling in the pulmonary circulation: Focus on ion channels. Antioxid Redox Signal 22: 537-552, 2015

5. Humbert M, Montani D, Evgenov OV and Simonneau G Definition and classification of pulmonary hypertension. Handb Exp Pharmacol 218: 3-29, 2013.

6. Veith C, Schermuly RT, Brandes RP and Weissmann N: Molecular mechanisms of hypoxia-inducible factor-induced pulmonary arterial smooth muscle cell alterations in pulmonary hypertension. J Physiol 594: 1167-1177, 2016.

7. Stenmark KR, Nozik-Grayck E, Gerasimovskaya E, Anwar A Li M, Riddle S and Frid M: The adventitia: Essential role in pulmonary vascular remodeling. Compr Physiol 1: 141-161, 2011.

8. Chazova I, Loyd JE, Zhdanov VS, Newman JH, Belenkov Y and Meyrick B: Pulmonary artery adventitial changes and venous involvement in primary pulmonary hypertension. Am J Pathol 146: 389-397, 1995.

9. Krick S, Hänze J, Eul B, Savai R, Seay U, Grimminger F, Lohmeyer J, Klepetko W, Seeger W and Rose F: Hypoxia-driven proliferation of human pulmonary artery fibroblasts: Cross-talk between HIF-1alpha and an autocrine angiotensin system. FASEB J 19: 857-859, 2005.

10. Stenmark KR, Davie N, Frid M, Gerasimovskaya E and Das M: Role of the adventitia in pulmonary vascular remodeling. Physiology 21: 134-145, 2006.

11. Das M, Bouchey DM, Moore MJ, Hopkins DC, Nemenoff RA and Stenmark KR: Hypoxia-induced proliferative response of vascular adventitial fibroblasts is dependent on g protein-mediated activation of mitogen-activated protein kinases. J Biol Chem 276: 15631-15640, 2001

12. Si Y, Ren J, Wang P, Rateri DL, Daugherty A, Shi XD, Kent KC and Liu B: Protein kinase C-delta mediates adventitial cell migration through regulation of monocyte chemoattractant protein-1 expression in a rat angioplasty model. Arterioscler Thromb Vasc Biol 32: 943-954, 2012

13. Conte E, Fruciano M, Fagone E, Gili E, Caraci F, Iemmolo M, Crimi $\mathrm{N}$ and Vancheri $\mathrm{C}$ : Inhibition of PI3K prevents the proliferation and differentiation of human lung fibroblasts into myofibroblasts: The role of class I P110 isoforms. PLoS One 6: e24663, 2011.

14. Das M, Dempsey EC, Reeves JT and Stenmark KR: Selective expansion of fibroblast subpopulations from pulmonary artery adventitia in response to hypoxia. Am J Physiol Lung Cell Mol Physiol 282: L976-L986, 2002.

15. Zhang L, Li Y, Liu Y, Wang X, Chen M, Xing Y and Zhu D: STAT3-mediated MMP-2 expression is required for 15-HETE-induced vascular adventitial fibroblast migration. J Steroid Biochem Mol Biol 149: 106-117, 2015.

16. Zhang L, Chen Y, Li G, Chen M, Huang W, Liu Y and Li Y: TGF- $\beta 1 /$ FGF-2 signaling mediates the 15-HETE-induced differentiation of adventitial fibroblasts into myofibroblasts. Lipids Health Dis 15: 2, 2016.

17. Li Y, Zhang L, Wang X, Chen M, Liu Y, Xing Y, Wang X, Gao $S$ and Zhu D: Elk-1-mediated 15-lipoxygenase expression is required for hypoxia-induced pulmonary vascular adventitial fibroblast dynamics. Acta Physiol (Oxf) 218: 276-289, 2016

18. Zhang Y, Talwar A, Tsang D, Bruchfeld A, Sadoughi A, Hu M, Omonuwa K, Cheng KF, Al-Abed Y and Miller EJ: Macrophage migration inhibitory factor mediates hypoxia-induced pulmonary hypertension. Mol Med 18: 215-223, 2012.

19. Anwar A, Li M, Frid MG, Kumar B, Gerasimovskaya EV, Riddle SR, McKeon BA, Thukaram R, Meyrick BO, Fini MA and Stenmark KR: Osteopontin is an endogenous modulator of the constitutively activated phenotype of pulmonary adventitial fibroblasts in hypoxic pulmonary hypertension. Am J Physiol Lung Cell Mol Physiol 303: L1-L11, 2012.

20. Yuan W, Liu W, Cai H, Sun X, Yang D, Xu F and Jin C: SB-431542, a specific inhibitor of the TGF- $\beta$ type I receptor inhibits hypoxia-induced proliferation of pulmonary artery adventitial fibroblasts. Pharmazie 71: 94-100, 2016.

21. Welsh DJ, Scott PH and Peacock AJ: p38 MAP kinase isoform activity and cell cycle regulators in the proliferative response of pulmonary and systemic artery fibroblasts to acute hypoxia. Pulm Pharmacol Ther 19: 128-138, 2006.
22. Carlin CM, Celnik DF, Pak O, Wadsworth R, Peacock AJ and Welsh DJ: Low-dose fluvastatin reverses the hypoxic pulmonary adventitial fibroblast phenotype in experimental pulmonary hypertension. Am J Respir Cell Mol Biol 47: 140-148, 2012.

23. Panzhinskiy E, Zawada WM, Stenmark KR and Das M: Hypoxia induces unique proliferative response in adventitial fibroblasts by activating PDGF $\beta$ receptor-JNK1 signalling. Cardiovasc Res 95: $356-365,2012$

24. Gerasimovskaya EV, Tucker DA and Stenmark KR: Activation of phosphatidylinositol 3-kinase, Akt, and mammalian target of rapamycin is necessary for hypoxia-induced pulmonary artery adventitial fibroblast proliferation. J Appl Physiol (1985) 98: 722-731, 2005.

25. Garat CV, Crossno JT Jr, Sullivan TM, Reusch JE and Klemm DJ: Inhibition of phosphatidylinositol 3-kinase/Akt signaling attenuates hypoxia-induced pulmonary artery remodeling and suppresses CREB depletion in arterial smooth muscle cells J Cardiovasc Pharmacol 62: 539-548, 2013.

26. Fan Z, Li C, Qin C, Xie L, Wang X, Gao Z, Qiangbacuozhen, Wang T, Yu L and Liu H: Role of the PI3K/AKT pathway in modulating cytoskeleton rearrangements and phenotype switching in rat pulmonary arterial vascular smooth muscle cells. DNA Cell Biol 33: 12-19, 2014.

27. Woodward HN, Anwar A, Riddle S, Taraseviciene-Stewart L, Fragoso M, Stenmark KR and Gerasimovskaya EV: PI3K, Rho, and ROCK play a key role in hypoxia-induced ATP release and ATP-stimulated angiogenic responses in pulmonary artery vasa vasorum endothelial cells. Am J Physiol Lung Cell Mol Physiol 297: L954-L964, 2009.

28. Stenmark KR, Tuder RM and El Kasmi KC: Metabolic reprogramming and inflammation act in concert to control vascular remodeling in hypoxic pulmonary hypertension. J Appl Physiol (1985) 119: 1164-1172, 2015.

29. Weichhart T and Säemann MD: The PI3K/Akt/mTOR pathway in innate immune cells: Emerging therapeutic applications. Ann Rheum Dis 67 (Suppl 3): iii70-iii74, 2008.

30. Committee for the Update of the Guide for the Care and Use of Laboratory Animals: Guide for the Care and Use of Laboratory Animals. 8th edition. The National Academies Press, Washington, DC, pp11-151, 2011.

31. Xu X, Wang X, Geng J, Li F, Yang T and Dai H: Rapamycin regulates connective tissue growth factor expression of lung epithelial cells via phosphoinositide 3-kinase. Exp Biol Med (Maywood) 238: 1082-1094, 2013.

32. Cantley LC: The phosphoinositide 3-kinase pathway. Science 296: 1655-1657, 2002.

33. Fang Y, Vilella-Bach M, Bachmann R, Flanigan A and Chen J: Phosphatidic acid-mediated mitogenic activation of mTOR signaling. Science 294: 1942-1945, 2001.

34. Gesbert F, Sellers WR, Signoretti S, Loda M and Griffin JD: $\mathrm{BCR} / \mathrm{ABL}$ regulates expression of the cyclin-dependent kinase inhibitor p27Kip1 through the phosphatidylinositol 3-kinase/ AKT pathway. J Biol Chem 275: 39223-39230, 2000.

35. Xu EZ, Kantores C, Ivanovska J, Engelberts D, Kavanagh BP, McNamara PJ and Jankov RP: Rescue treatment with a Rho-kinase inhibitor normalizes right ventricular function and reverses remodeling in juvenile rats with chronic pulmonary hypertension. Am J Physiol Heart Circ Physiol 299: H1854-H1864, 2010.

36. Berven LA and Crouch MF: Cellular function of p70S6K: A role in regulating cell motility. Immunol Cell Biol 78: 447-451, 2000

37. Marinov M, Fischer B and Arcaro A: Targeting mTOR signaling in lung cancer. Crit Rev Oncol Hematol 63: 172-182, 2007.

38. Maira SM, Stauffer F, Brueggen J, Furet P, Schnell C, Fritsch C, Brachmann $\mathrm{S}$, Chène $\mathrm{P}$, De Pover $\mathrm{A}$, Schoemaker $\mathrm{K}$, et al: Identification and characterization of NVP-BEZ235, a new orally available dual phosphatidylinositol 3-kinase/mammalian target of rapamycin inhibitor with potent in vivo antitumor activity. Mol Cancer Ther 7: 1851-1863, 2008.

39. Cui B, Tao J and Yang Y: Studies on the expression patterns of class I PI3K catalytic subunits and its prognostic significance in colorectal cancer. Cell Biochem Biophys 62: 47-54, 2012.

40. Shimoda LA and Laurie SS: HIF and pulmonary vascular responses to hypoxia. J Appl Physiol (1985) 116: 867-874, 2014.

41. Rogers SC, Said A, Corcuera D, McLaughlin D, Kell P and Doctor A: Hypoxia limits antioxidant capacity in red blood cells by altering glycolytic pathway dominance. FASEB J 23: 3159-3170, 2009.

This work is licensed under a Creative Commons Attribution-NonCommercial-NoDerivatives 4.0 International (CC BY-NC-ND 4.0) License. 